\title{
Enraizamento de estacas lenhosas de três cultivares de mirtileiro com diferentes concentrações de AIB
}

\author{
Rooting of hardwood cuttings of three blueberry cultivars with different concentrations of IBA
}

\author{
Gerson Kleinick Vignolo ${ }^{I}$ Doralice Lobato de Oliveira Fischer ${ }^{I}$ Vanessa Fernandes Araujo ${ }^{\mathrm{I}}$ \\ Roberta Jeske Kunde ${ }^{\mathrm{I}}$ Luis Eduardo Corrêa Antunes ${ }^{\mathrm{II}}$
}

\section{RESUMO}

Comercialmente, a propagação do mirtileiro por meio de estacas é o método mais utilizado, proporcionando resultados diversos de acordo com a cultivar e a concentração de ácido indolbutírico (AIB) utilizada. Objetivou-se, com este trabalho, avaliar o efeito do ácido indolbutírico no enraizamento de estacas lenhosas de mirtileiro. O material utilizado constituiuse de segmentos de ramos secundários, com quatro gemas $e$ diâmetro médio de 4,5mm. O delineamento experimental foi completamente casualizado, em fatorial $5 \times 3$, com cinco concentrações de AIB (0; 1.500; 3.000, 4.500 e 6.000mg $\left.L^{-1}\right) e$ três cultivares (Delite, Bluebelle e Briteblue), com quatro repetições e dez estacas por parcela. Após o preparo das estacas, a base destas foi imersa, por 10 segundos, na solução de AIB, sendo colocadas para enraizar em uma mistura de areia de granulometria grossa e substrato comercial Turfa Fértil ${ }^{\circledR}$ com pH de 5,5 na proporção de 1:1(v/v), com irrigação manual. Após 138 dias da instalação do experimento, avaliaram-se a porcentagem de estacas enraizadas, número médio de raízes por estaca, comprimento da maior raiz, número médio de brotações, comprimento da maior brotação e a porcentagem de estacas sobreviventes. De acordo com os resultados obtidos, não foi verificada interação entre os diferentes fatores. Verificaram-se diferenças entre as cultivares nas variáveis comprimento da maior raiz, número médio de raízes por estaca e para porcentagem de estacas sobreviventes. Para concentração de AIB, verificou-se, por meio da análise de regressão, um comportamento linear crescente para as variáveis porcentagem de estacas sobreviventes e enraizadas, porém a resposta foi quadrática para comprimento da maior raiz. Conclui-se que a utilização de AIB em concentração de até $6.000 \mathrm{mg} \mathrm{L}^{-1}$ não é suficiente para expressar o máximo potencial de enraizamento nas estacas de mirtileiro das cultivares Delite, Bluebelle e Briteblue.

\author{
Palavras-chave: Vaccinium ashei, regulador vegetal, \\ propagação vegetativa.
}

\section{ABSTRACT}

Commercially, propagation of blueberry by cutting is the very usual method, which gives a range of results according to the cultivar. This research aimed to evaluate the effect of indol-butyric acid (IBA) on rooting of blueberry hardwood cuttings. It was used segments of secondary branches with four buds and mean diameter of $4.5 \mathrm{~mm}$. The experimental design was totally randomized in a $5 \times 3$ factorial, five concentrations of IBA (0; 1500; 3000; 4500 and $\left.6000 \mathrm{mg} \mathrm{L}^{-1}\right)$ and three cultivars (Delite, Bluebelle and Briteblue). It was used four replications and ten cuttings per plot. After cutting, the base of the cuttings was dipped for 10 seconds into a solution of IBA. Then, they were put to root in a mix of thick sand and commercial substrate Turfa Fertil ${ }^{\circledR}$ (1:1) with pH 5.5 and manually irrigated. After 138 days from trial installation, percentage of rooted cuttings, number of root per cutting, length of the largest root, number of shoots, length of the largest shoot and percentage of surviving cuttings were evaluated. According to the results it was not verified interaction among different factors. It was verified difference among cultivars only in the length of the largest root, number of root per cutting and percentage of surviving cuttings. For concentration of IBA, it was verified by regression analysis, a linear behavior for the variables increasing rooted and survived, but the response was quadratic for the longest root length. It was concluded that the concentration up to $6000 \mathrm{mg} \mathrm{L}^{-1}$ IBA is not sufficient to express the maximum rooting potential of the blueberry cuttings cultivars Delite, Bluebelle and Briteblue.

Key words: Vaccinium ashei, plant growth regulator, vegetative propagation.

'Programa de Pós-graduação em Agronomia, Universidade Federal de Pelotas (UFPel), Pelotas, RS, Brasil.

"Embrapa Clima Temperado, BR 392, km 78, 96001-970, Pelotas, RS, Brasil. E-mail: luis.eduardo@cpact.embrapa.br. Autor para correspondência. 


\section{INTRODUÇÃO}

O mirtileiro (Vaccinium ashei) é uma frutífera da família Ericaceae, nativa dos Estados Unidos. É uma dicotiledônea perene com um sistema radicular relativamente superficial e ramos lenhosos que se originam da coroa da planta. Seu fruto é de cor azul-escura com tamanho variável dependendo da composição genética das plantas e das condições climáticas (BOWLING, 2005).

Na América do Sul, as áreas cultivadas com mirtileiro vêm aumentando, principalmente no Chile e Argentina, as quais até 2005 somavam uma área de aproximadamente 8.300ha, seguidos pelo Uruguai com 400ha (ZITO, 2006). No Brasil, a cultura foi recentemente introduzida, porém, através de informações obtidas de pesquisadores e extensionistas, estima-se que a área cultivada está ao redor de 100ha (PAGOT, 2006). Aárea plantada ainda é pequena, principalmente devido à indisponibilidade, à qualidade e ao preço das mudas, situação decorrente da dificuldade de propagação da maioria das cultivares (TREVISAN et al., 2008).

As técnicas de propagação do mirtileiro incluem o uso de sementes, estacas lenhosas e herbáceas, bem como a propagação por enxertia e alporquia. A estaquia é o método comercialmente utilizado para propagação de mirtileiro, porém, para criação de novas cultivares, utiliza-se propagação por sementes (TREHANE, 2004).

A utilização de ramos lenhosos, provenientes de plantas dormentes, é uma boa opção para a formação de mudas de mirtileiro, com a vantagem de se aproveitarem os ramos eliminados na poda de inverno (CAMPOS et al., 2005). A capacidade de uma estaca emitir raízes é função de fatores endógenos e das condições ambientais proporcionadas ao enraizamento. Entre tais fatores, os reguladores vegetais são de importância fundamental, destacando-se as auxinas por fazerem parte do grupo que apresenta o maior efeito na formação de raízes em estacas (FACHINELLO et al., 2005). Uma das formas de aplicação exógena de auxina, com intuito de possibilitar aumento da capacidade de enraizamento de estacas de espécies de difícil enraizamento, é a utilização do ácido indolbutírico (AIB), que é a auxina mais comumente utilizada na indução do enraizamento adventício (VILLA et al., 2003) de estacas das mais diversas culturas.

Diante do exposto, objetivou-se, com este trabalho, avaliar o efeito do ácido indolbutírico (AIB) no enraizamento de estacas lenhosas de mirtileiro.

\section{MATERIAL E MÉTODOS}

O experimento foi conduzido em estufa agrícola na Frutplan Mudas Ltda., Pelotas-RS, no período de agosto a dezembro de 2009. Foram utilizadas estacas lenhosas, das cultivares 'Delite', 'Bluebelle’ e 'Briteblue', provenientes de ramos laterais oriundos de brotações da primavera anterior.

Os ramos foram coletados no início da primeira quinzena de agosto, no período da manhã, e acondicionados em baldes com água. Posteriormente, foram segmentados em estacas sem folhas com quatro gemas, com comprimento aproximado de $10 \mathrm{~cm}$ e diâmetro médio de 4,5mm, descartando-se a sua parte basal e apical.

Com o auxílio de um canivete, foram feitas duas lesões superficiais, uma de cada lado na base das estacas. Posteriormente, as bases foram imersas, por 10 segundos, em solução comercial de AIB (Clone $\mathrm{Gel}^{\circledR}$ ), nas concentrações de $0 ; 1.500 ; 3.000 ; 4.500$ e $6.000 \mathrm{mg} \mathrm{L}^{-1}$ adquiridas já nestas concentrações, não precisando serem feitas diluições. As estacas foram colocadas para enraizar em bancadas de madeira de 2,45 x 1,23m, com $20 \mathrm{~cm}$ de altura, contendo uma camada de pedra brita no 2 sob tela plástica de $2 \mathrm{~mm}$ no fundo, para facilitar a drenagem, e uma mistura de areia de granulometria grossa e substrato comercial Turfa Fértil ${ }^{\circledR}$ na proporção de 1:1 como substrato. Para a concentração testemunha, foi utilizada apenas água destilada. Após o plantio, as estacas foram pulverizadas com Orthocid ${ }^{\circledR} 500$ PM (2,5g L-1 de água), sendo esta mesma operação repetida após sete dias.

O material propagativo foi mantido em ambiente protegido, sob sistema manual de irrigação por microaspersão, acionado quando necessário. $\mathrm{O}$ pH da água utilizada para irrigação foi corrigido para aproximadamente 5,0 com Quimifol P 30 ${ }^{\circledR}$ 5,0, conforme recomendação de CAMPOS et al. (2005). Após 138 dias da instalação do experimento, avaliaram-se a porcentagem de estacas enraizadas, número médio de raízes por estaca, comprimento da maior raiz, número médio de brotações, comprimento da maior brotação e a porcentagem de estacas sobreviventes.

O delineamento experimental utilizado foi em blocos ao acaso, com três cultivares ('Delite', 'Bluebelle' e 'Briteblue') e cinco concentrações de AIB (0; $1.500 ; 3.000$, 4.500 e $6.000 \mathrm{mg} \mathrm{L}^{-1}$ ), com quatro repetições e dez estacas por parcela. Os dados referentes às cultivares foram submetidos à análise da variância pelo teste $\mathrm{F}$ e, quando significativos, foram submetidos à comparação entre as médias pelo teste de Tukey a $5 \%$ de probabilidade. O fator quantitativo concentração de AIB foi submetido à regressão polinomial. Foi utilizado, para as análises, o programa estatístico WinStat, versão 2.0 (MACHADO \& CONCEIÇÃO, 2003). 


\section{RESULTADOS E DISCUSSÃO}

Houve efeito das cultivares sobre a porcentagem de estacas sobreviventes de mirtileiro, no qual as cultivares 'Briteblue' $(84,5 \%)$ e 'Blueblle' (79,5\%) foram superiores à 'Delite', a qual apresentou $66 \%$ de sobrevivência (Tabela 1). Possivelmente, as cultivares 'Briteblue' e 'Bluebelle' tenham maiores quantidades de reservas nutritivas do que 'Delite' para suportar o desenvolvimento das raízes e das brotações, proporcionando assim maior porcentagem de sobrevivência das estacas.

Com relação à porcentagem de enraizamento, as cultivares apresentaram comportamento semelhante, obtendo-se média de $59 \%$, $58 \%$ e $46 \%$ de estacas enraizadas para as cultivares 'Briteblue', 'Bluebelle' e 'Delite', respectivamente (Tabela 1). Resultado similar quanto ao efeito do ácido indolbutírico e da cultivar no enraizamento de estacas lenhosas de mirtileiro foi relatado por FISCHER et al. (2008), os quais não observaram diferença significativa entre as médias das cultivares 'Bluebelle' (75,5\%) e 'Delite' (69\%). TREVISAN et al. (2008), ao estudarem o enraizamento de estacas herbáceas de sete cultivares de mirtileiro sob o efeito de diferentes concentrações de AIB, constataram que os resultados foram bastante variáveis entre as cultivares. No entanto, não observaram influência do AIB no enraizamento, com percentuais variando de zero a $51,6 \%$.

Esses resultados concordam em parte com o relato feito por BOUNOUS (2003), de que, apesar de ser frequente o emprego de reguladores vegetais para a promoção do enraizamento em mirtileiro, há controvérsia em sua eficácia. Neste trabalho, foram obtidos resultados diferenciados quanto ao uso do AIB, provando a sua eficácia e incremento na promoção do enraizamento.

Para algumas cultivares, os teores endógenos de auxinas produzidos pelas gemas e folhas pode ser suficiente para a desdiferenciação e a indução da divisão celular, independentemente da aplicação exógena de auxina. Esses resultados estão de acordo com FACHINELLO et al. (2005), pois, segundo estes autores, o teor adequado de auxina exógena, para o estímulo do enraizamento, depende da concentração existente no tecido. Respostas diferenciadas, entre cultivares da mesma espécie, quanto a capacidade de formar raízes, têm sido relatadas por vários autores, entre eles TOFANELLI et al. (2002) e DUTRA et al. (2002).

Houve incremento na porcentagem de estacas sobreviventes e enraizadas, à medida que se aumentou a concentração de AIB, demonstrando ser possível obter resultados ainda melhores com o acréscimo das concentrações utilizadas (Figura 1). Esses resultados corroboram FISCHER et al. (2008) que constataram maior enraizamento $(92,5 \%)$ na concentração de $8.000 \mathrm{mg} \mathrm{L}^{-1}$ para a cultivar 'Delite', quando comparado às concentrações de $0,1.000,2.000$ e $4.000 \mathrm{mg} \mathrm{L}^{-1}$ de AIB, as quais proporcionaram $55 \%$, $62,5 \%, 62,5 \%$ e $72,5 \%$ de enraizamento, respectivamente. Segundo TAIZ \& ZEIGER (2002), altos níveis de auxinas estimulam não só a iniciação de raízes laterais, mas também a formação de raízes adventícias e o efeito de estímulo da auxina na formação dessas raízes tem sido de extrema importância na horticultura, permitindo dessa forma a propagação vegetativa de plantas por estaquia.

No entanto, TREVISAN et al. (2008), ao testar concentrações de até $7.500 \mathrm{mg} \mathrm{L}^{-1}$, relataram não haver incremento de enraizamento ao aumentar a concentração de AIB. Os autores relacionam a baixa porcentagem de enraizamento a períodos de estiagem que antecederam a época de coleta das estacas, interferindo assim na condição fisiológica da planta matriz, no teor de reservas e de nutrientes.

No presente trabalho, os ramos foram provenientes de matrizeiro com ferti-irrigação, o que deve ter favorecido uma melhor disponibilidade de nutrientes, proporcionando assim um balanço hormonal mais equilibrado. De acordo com GIANELLO

Tabela 1 - Estacas sobreviventes, enraizadas e comprimento da maior raiz de três cultivares de mirtileiro sob diferentes concentrações de AIB. Pelotas-RS, 2011.

\begin{tabular}{lccc}
\hline Cultivar & Estacas sobreviventes (\%) & Estacas enraizadas (\%) & Comprimento da maior raiz (cm) \\
\hline 'Briteblue' & $84,5 \mathrm{a}$ & $59^{\text {ns }}$ & $7,33 \mathrm{a}$ \\
'Bluebelle' & $79,5 \mathrm{a}$ & 58 & $6,59 \mathrm{ab}$ \\
'Delite' & $66,0 \mathrm{~b}$ & 46 & $5,91 \mathrm{~b}$ \\
CV (\%) & 22,03 & 34,46 & 26,30 \\
\hline
\end{tabular}

Médias seguidas de mesma letra, nas colunas, não diferem significativamente entre si, pelo teste de Tukey (5\%). Não significativo a 5\% de probabilidade de erro.

Ciência Rural, v.42, n.5, mai, 2012. 


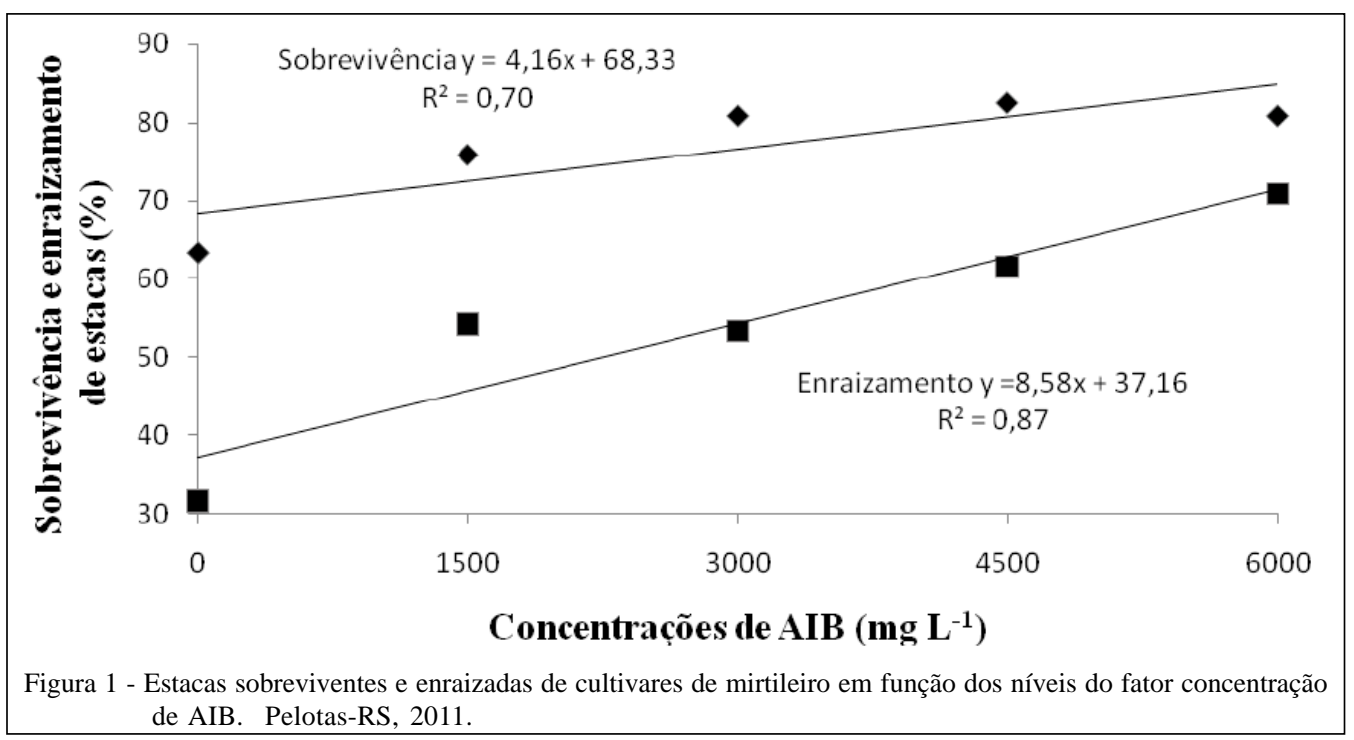

\& GIASSON et al. (2008), o desenvolvimento vegetativo é muito intenso durante o período de crescimento, fazendo com que ocorra uma alta demanda por nutrientes. Por isso, quando há déficit de nutrição durante esse período vegetativo, a planta pode não expressar o seu potencial genético em função dos fatores ambientais adversos.

O comprimento da maior raiz, na cultivar 'Briteblue' $(7,33 \mathrm{~cm})$, foi superior à 'Delite' $(5,61 \mathrm{~cm})$, porém não diferiu de 'Bluebelle’(6,59) (Tabela 1). De acordo com FISCHER et al. (2008), a cultivar 'Bluebelle' apresenta comprimento da maior raiz superior à 'Delite', obtendo médias de 4,3 e $3,5 \mathrm{~cm}$, respectivamente.

As cultivares 'Briteblue' e 'Delite' apresentaram 4,13 e 3,97 raízes por estaca, sendo superiores à 'Bluebelle' (Tabela 2). CAMPOS et al. (2005) consideram que o número de raízes por estaca é um dado muito importante no enraizamento, uma vez que o estabelecimento das mudas de mirtileiro não está relacionado somente ao tamanho das raízes, mas também com sua quantidade.
O comprimento da maior raiz de estacas de mirtileiro foi influenciado pelas diferentes concentrações de AIB, apresentando comportamento quadrático com ponto de máxima de $4.250 \mathrm{mg} \mathrm{L}^{-1}$, no qual, acima desta concentração, houve redução do comprimento radical (Figura 2). Apesar de terem sido observadas maiores porcentagens de sobrevivência e enraizamento de estacas com o aumento das concentrações de AIB (Figura 1), observa-se que, para o comprimento radical, as concentrações mais elevadas foram excessivas. FACHINELLO et al. (2005) relatam que o aumento da concentração de auxina exógena, aplicada em estacas, estimula a formação de raízes até um valor máximo, a partir do qual qualquer acréscimo tem efeito inibitório. $\mathrm{O}$ teor adequado de auxina exógena, para estímulo do enraizamento, depende da espécie e da concentração de auxina existente no tecido.

Não foram observadas diferenças significativas para as variáveis comprimento da maior brotação e número médio de brotações por estaca (Tabela 2). Sabe-se que a brotação das gemas não deve

Tabela 2 - Número de raízes, comprimento da maior brotação e número de brotações de três cultivares de mirtileiro sob diferentes concentrações de AIB. Pelotas-RS, 2011.

\begin{tabular}{lccc}
\hline Cultivar & Número médio de raízes por estaca & Comprimento da maior brotação $(\mathrm{cm})$ & Número médio de brotações por estaca \\
'Briteblue' & $4,13 \mathrm{a}$ & 2,20 & 1,98 \\
'Bluebelle' & $2,76 \mathrm{~b}$ & $2,49^{\text {ns }}$ & $2,20^{\mathrm{ns}}$ \\
'Delite' & $3,97 \mathrm{a}$ & 3,17 & 1,89 \\
CV $(\%)$ & 37,92 & 66,71 & 29,88 \\
\hline
\end{tabular}

Médias seguidas de mesma letra, nas colunas, não diferem significativamente entre si, pelo teste de Tukey (5\%). ${ }^{\text {ns }}$ Não significativo a $5 \%$ de probabilidade de erro.

Ciência Rural, v.42, n.5, mai, 2012. 


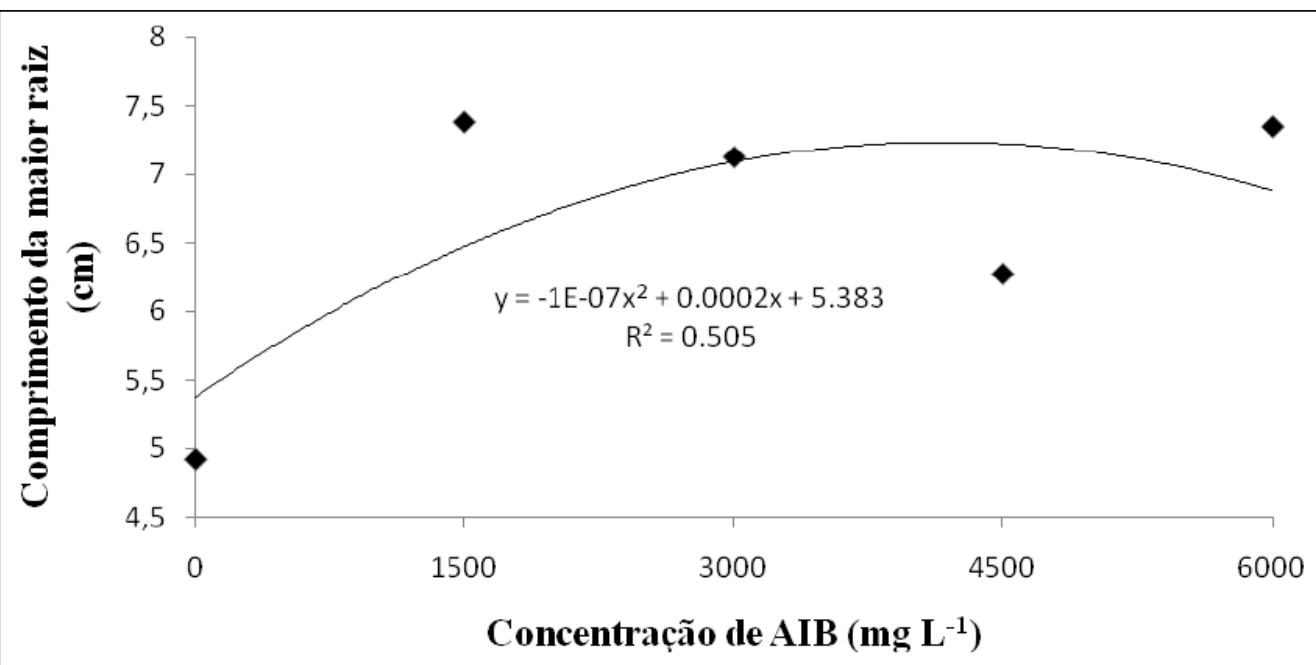

Figura 2 - Comprimento da maior raiz de cultivares de mirtileiro em função dos níveis do fator concentração de AIB. Pelotas-RS, 2011.

ocorrer antes do enraizamento das estacas, pois prejudica a formação de raízes (FACHINELLO et al., 2005).

\section{CONCLUSÃO}

As cultivares de mirtileiro 'Bluebelle', 'Briteblue' e 'Delite' apresentam aumento de estacas sobreviventes e enraizadas com o incremento da concentração de AIB. O aumento da concentração de AIB até $4250 \mathrm{mg} \mathrm{L}^{-1}$ proporciona incremento no comprimento do sistema radicular. As cultivares 'Briteblue' e 'Bluebelle' apresentam maior porcentagem de estacas sobreviventes do que 'Delite'. A cultivar 'Briteblue' apresenta comprimento radicular superior à 'Delite' e número médio de raízes por estaca maior que 'Bluebelle'. A propagação por estacas lenhosas é viável, obtendo-se, dependendo da cultivar, de $46 \%$ a $59 \%$ de enraizamento.

\section{REFERÊNCIAS}

BOUNOUS, G. Tecniche di produzione del mirtilo gigante in Italia. Frutticoltura, Bologna, n.11, p.24-30, 2003.

BOWLING, B.L. The berry growers's companion. Oregon: Timber, 2005. 284p.

CAMPOS, A.D. et al. Enraizamento de estacas de mirtilo provenientes de ramos lenhosos. Pelotas: Embrapa Clima Temperado, 2005. 6p. (Comunicado técnico, 133).

DUTRA, L.F. et al. Época de coleta, ácido indolbutírico e triptofano no enraizamento de estacas de pessegueiro. Scientia Agrícola, Piracicaba, v.59, n.2, p.296-304, 2002. Disponível em: <http:// www.scielo.br/scielo.php?script=sci_arttext\&pid=S0103- 90162002000200019\&lang=pt $>$. Acesso em: 04 fev. 2011. doi: 10.1590/S0103-90162002000200019.

FACHINELLO, J.C. et al. Propagação vegetativa por estaquia. In: FACHINELlO, J.C. et al. Propagação de plantas frutíferas. Brasília: Embrapa Informações Tecnológicas, 2005. p.69-109.

FISCHER, D.L.O. et al. Efeito do ácido indolbutírico e da cultivar no enraizamento de estacas lenhosas de mirtilo. Revista Brasileira de Fruticultura, Jaboticabal, v.30, n.2, p.285289, 2008. Disponível em: <http://www.scielo.br/ scielo.php? script=sci_arttext\&pid=S 0100 29452008000200003\&lang=pt $>$. Acesso em: 20 mar. 2011. doi: $10.1590 / \mathrm{S} 0100-29452008000200003$.

GIANELLO, C.; GIASSON, E. Fatores que afetam o rendimento das culturas e sistemas de cultivos. In: BISSANI, C.A. et al. Fertilidade dos solos e manejo da adubação de culturas. 3.ed. Porto Alegre: Metrópole, 2008. p.21-32.

MACHADO, A.A.; CONCEIÇÃO, A.R. Sistema de análise estatística para windows. WinStat. Pelotas: UFPel, 2003. Versão 2.0

PAGOT, E. Cultivo de pequenas frutas: amora-preta, framboesa e mirtilo. Porto Alegre: EMATER/RS-ASCAR, 2006. 41p.

TAIZ, L; ZEIGER, E. Auxina: o hormônio de crescimento. In: Fisiologia vegetal. 3. ed. São Paulo: ARTMED, 2002. p.450-484.

TOFANELLI, M.B.D. et al. Efeito do ácido indolbutírico no enraizamento de estacas de ramos semilenhosos de pessegueiro. Pesquisa Agropecuária Brasileira, Brasília, v.37 n.7, p.939944, 2002. Disponível em: <http://www.scielo.br/ scielo.php? script =sci_art text \& pid=S 0100 204X2002000700007\&lang=pt $>$. Acesso em: 12 jan. 2011. doi: 10.1590/S0100-204X2002000700007. 
TREHANE, J. Blueberries, cramberries and other vacciniums. Cambridge: Royal Horticultural Society, 2004. 256p.

TREVISAN, R. et al. Enraizamento de estacas herbáceas de mirtilo: influência da lesão na base e do ácido indolbutírico. Ciência e Agrotecnologia, Lavras, v.32, n.2, p.402-406, 2008. Disponível em: <http://www.scielo.br/ scielo.ph p ? script=sci_art text \& pid = S 1413 70542008000200009\&lang=pt $>$. Acesso em: 22 mar. 2011. doi: 10.1590/S1413-70542008000200009.
VILLA, F. et al. Propagação de amoreira-preta utilizando estacas lenhosas. Ciência e Agrotecnologia, Lavras, v.27, n.4, p.829834, 2003. Disponível em: <http://www.scielo.br/ sciel o.ph p ? c ri pt=sci_art text \& pid=S 1413 70542003000400013\&lang=pt $>$. Acesso em: 21 abr. 2011. doi: 10.1590/S1413-70542003000400013.

ZITO, C.M. Producción de arándanos en Sudamérica. In: SIMPOSIO NACIONAL DO MORANGO, 3.; ENCONTRO DE PESQUENAS FRUTAS E FRUTAS NATIVAS DO MERCOSUL, 2., 2006, Pelotas, RS. (Ed.). ANTUNES, L.E.C.; RASEIRA, M. do C.B. Palestras... Pelotas: Embrapa Clima Temperado, 2006. p.97-100. (Documentos, 171). 